\title{
OS EXCLuíDOS DO NOSSO INTERIOR
}

\section{MÁRCIO JOSÉ SILVA ${ }^{1}$}
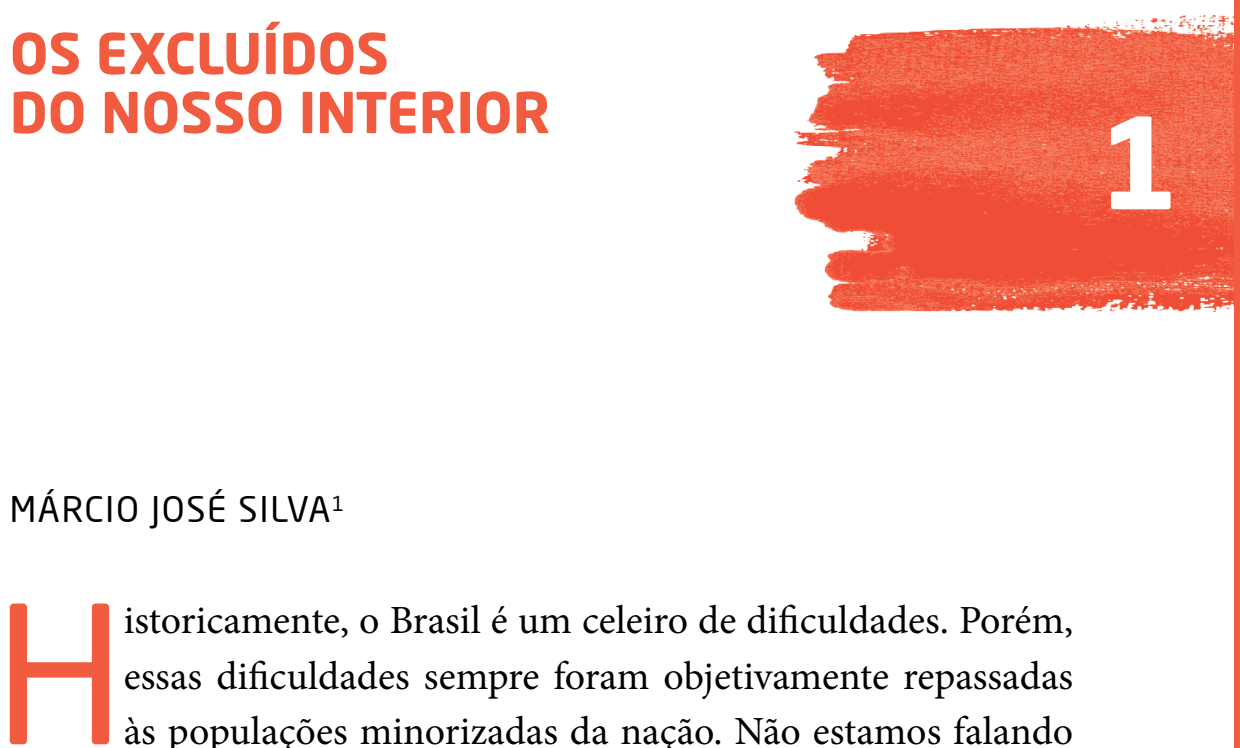

istoricamente, o Brasil é um celeiro de dificuldades. Porém, essas dificuldades sempre foram objetivamente repassadas às populações minorizadas da nação. Não estamos falando de um punhado de pessoas privadas de seus direitos fundamentais, mas de milhões que, desde sempre, estiveram aquém da cidadania preconizada em diplomas jurídicos. Sim, aos milhões, em cifras absolutas, mais de $50 \%$ da população são mulheres ou negros, grupos que são justamente esquecidos, banidos e punidos pela ignóbil razão de serem tais, humanos que não se enquadram nas vias do sucesso social: homem, branco e rico; qualquer pessoa fora desse padrão será somente 'outro', no máximo 'alguém', provavelmente um dos muitos 'ninguéns' que grassam no Brasil.

Porém, mesmo sendo os minorizados do Brasil um número tão expressivo, a estratégia política brasileira de invisibilização pelo Estado, especialmente em seu discurso ideológico é uma demonstração do quão insignificantes essas pessoas são feitas em nome de um projeto de poder inquietante. Há, por exemplo, uma propaganda institucional do

1 Programa de Mestrado em Educação, Arte e História da Cultura da Universidade Presbiteriana Mackenzie. 
Ministério da Educação, acerca do novo modelo de ensino médio, que o governo aprovou no Congresso Nacional, na qual jovens discutem sobre as vantagens do novo modelo, à base da Base Nacional Comum Curricular, cuja discussão, notem: 'já começou' (MEC, canal YouTube, jan. 2017). Não estamos falando de algo concluso, mas algo ainda desconhecido. Outro argumento falacioso: jovens com os bordões de sempre ('não quero estudar um monte de coisa que não tem ligação com o que quero para meu futuro' - MEC, canal YouTube, jan. 2017), mas sem qualquer realidade concreta possível de discussão, porque a verdade é que esse modelo é o esvaziamento e desfuncionalização da escola, à base de premissas que são apenas ilações, não fatos.

A mais hedionda das propagandas dá conta de que há uma liberdade para estudos, mas não se explica o que é essa liberdade. Fala-se sobre a escolha quanto à vocação profissional, porém, não diz quem ofereceu ou oferecerá essa orientação. O mais deplorável é o que se apresenta: ' $72 \%$ dos brasileiros aprovam' esse modelo, não obstante, não se informa quem são esses que o aprovam e, considerando o alto grau de aprovação, é absurdo prestarem uma informação como essa (MEC, canal YouTube, dez. 2016). Todavia, é evidente o motivo: iludir, enganar, engodar as pessoas para apoiarem o desmantelamento da educação, especialmente a pública, que sofre com séculos de descaso. Em nenhum momento fala-se, por exemplo, em quê a rede privada passará por essas 'reformas', se é que passará. Aos pobres, contudo, é fato que serão, novamente, tributados com a política pública mais eficiente do Estado: a da exclusão.

\section{RAÍZES EDUCACIONAIS BRASILEIRAS}

Darcy Ribeiro, antropólogo brasileiro e homem que dedicou boa parte de sua vida à educação, denunciou na $29^{a}$ Reunião Anual 
da Sociedade Brasileira para o Progresso da Ciência (SBPC), em 1977, o seguinte: "Em consequência, a crise educacional do Brasil, da qual tanto se fala, não é uma crise, é um programa. Um programa em curso, cujos frutos, amanhã, falarão por si mesmos" (Ribeiro, 2011, p. 56). Darcy Ribeiro comentava sobre a derrocada da escola pública, iniciada anos antes e que seguia um curso de queda irreversível. Contudo, segundo ele, isso não era uma mera casualidade ou intempestividade de crises econômicas ou estruturais que vez por outra acometem os países. Era algo estrategicamente calculado.

O regime de 1964 levou os acordos com os Estados Unidos (acordos MEC-USAID) a extremos que desmantelaram a escola pública e a universidade. $\mathrm{O}$ discurso ideológico era de equiparação e modernização em consonância com o sistema estadunidense, algo que jamais se concretizaria.

Como safra dessa política pública educacional, no final da década de 1970, quando Ribeiro falava, os Estados Unidos encaminhavam à Universidade cerca de $70 \%$ dos seus jovens em idade apta para tal (18-24 anos). Cuba rumava para a totalidade de discentes na Universidade. Uma obviedade que não escapava à percepção de Ribeiro era o fato de sermos 100 anos mais antigos que os Estados Unidos e termos um déficit de 50 anos em relação a eles quanto à educação. Em contrapartida, a professora Romanelli, analisando o contexto educacional brasileiro em 1970, deuse conta de uma população entre 20-29 anos de idade, somente $2,79 \%$ tinham o sucesso de ascender ao nível superior (Romanelli, 2013, p. 83).

Passados anos, temos um panorama assombroso: Cuba erradicou o analfabetismo e garantiu acesso à Universidade para todos os seus cidadãos. Argentina assegurou acesso a $67 \%$ dos jovens, Uruguai com $64 \%$ e Chile com $52 \%$, sendo que os três 
têm índice de analfabetismo entre $2 \%$ e 3,5\%. O Brasil, uma potência econômica, o mais rico da América do Sul tem taxa de acesso à Universidade média de 30\% (falar em 30\% é estratégia política porque os dados populacionais são tratados na razão de ' $x$ ' por 1.000 habitantes, logo, 30\% equivale a 3\% em números efetivos, conforme o censo escolar de 2015 do MEC, disponível em: <http://portal.inep.gov.br/sinopses-estatisticas-da-educacao-basica $>$ ) e analfabetismo de 11,1\% (Unesco, 2013, p. 134-137, 169,170). Seria um ledo engano nosso supor que essa realidade educacional simplesmente seguiu o curso natural das coisas. Como poderia ser possível o país mais rico do continente sul-americano estar entre os que têm a pior taxa de acesso ao ensino superior, sendo que só conseguiu universalizar o acesso à educação fundamental já no século XXI?

A resposta passa pelo fato de que não temos, na educação básica, o necessário treinamento e preparo, uma escola que seja holística, mas uma materialização de um projeto programado para que existam duas realidades: a escola dos que podem pagar pela educação e a 'escola dos outros'. Disse Bourdieu (1993, p. 481):

Deste conjunto, percebemos habitualmente só os extremos: por um lado as escolas precárias, que se multiplicam apressadamente nos subúrbios cada vez mais pobres, para acolher cada vez mais alunos, cada vez menos preparados culturalmente, sem muito a ver com o idealizado com o curso escolar [...]; do outro, colégios selecionados, onde alunos das famílias mais abastadas podem ter uma vida escolar bastante parecida com aquela de seus pais e avós.

Embora estejamos separados por um oceano, Brasil e França são partícipes do mesmo problema que acomete o sistema de ensi- 
no. Essa dicotomia incontestável que permite a alguns uma mobilidade social, estranhamente aos que não necessitam desta, ao passo que os que dependem de uma oportunidade são tolhidos, seja pela precariedade em que se encontra a escola brasileira, notadamente a pública, seja pelo descompasso da realidade do discente com o currículo escolar que engloba tudo, exceto a realidade popular, a língua e linguagem do pobre, suas expressões artísticas, tidas como desnecessárias ou mesmo desprezíveis porque são fruto do suor e sangue, não da tinta e do ateliê.

A conta dessa dualidade nefasta é presente nos índices distorcidos brasileiros, quanto à economia, pobreza e discriminação. Toda nossa pretensa igualdade, preconizada na lei, desde a Constituição Federal até as leis ordinárias, torna-se uma retórica de excelente redundância e, pior, vazia. Fala-se muito sobre o mesmo, sem com isso produzir um resultado que efetive a cidadania para milhões. De fato, há muitos milhões de brasileiros que ficaram à parte dessa cidadania tão falada, tão bela, mas inexistente para muitos. O Brasil é, assim, o país de poucos, embora tenha espaço suficiente para todos.

\section{EDUCAÇÃO EM PANORAMA}

Montesquieu relembra que as primeiras leis que os humanos recebem são as leis da educação, iniciadas no ambiente familiar. Posteriormente, ele define o que diferirá em cada sistema de governo: nas monarquias, cujo propósito é incutir a honra qual princípio motor de vida, a educação intensa se dá mais no âmbito doméstico, sendo a escola uma extensão ou um polimento do que a família fez. Os governos despóticos, que têm como base o medo, cuidarão de domesticar o coração humano, a fim de torná-lo um servo dócil e 
quieto, não há espaço para que este pense, fale ou aja demais; requer-se dele a submissão apenas. Por fim, na república, cuja força motriz é a virtude política, não apenas a existência de 'pessoas de bem', mas de pessoas que vivem para o bem comum, da nação, a educação assumirá um papel peremptório: treinar o cidadão para amar antes ao interesse público do que o seu próprio; incutir-lhe que o amor aos interesses da pátria é mais importantes que anseios egoístas; por fim, treiná-lo-á à abnegação e renúncia de suas vontades e desejos para que o bem comum seja posto como mais importante. Que sonho!

A partir de então, a educação ganharia contornos totalmente novos. Ela não pode ser apenas um acessório, deve fazer parte da vida do cidadão. Isso foi bem assimilado pelo mundo daqueles dias, especialmente após a Revolução Francesa (1789-1799), que deu uma demonstração do perigo que é deixar as paixões populares, vorazes e descontroladas, sem a devida educação, soltas: milhares de mortos, pilhagens e massacres, caos políticos na França. Foi uma hecatombe, mas foi a melhor de todas porque o mundo pós -Revolução Francesa era outro. Grilhões antigos foram rompidos, ideias novas floresceram, liberdades foram asseguradas e, à base do primado da lei, não mais existiam dois tipos de iguais, um plebeu, desprovido de tudo, e o nobre ou alto clérigo recoberto de privilégios. Mas ela trouxe consigo algumas amarras novas: a visão fria de mundo, a concepção crua de humanidade a cegueira das paixões e arrogâncias humanas e tipos específicos de desiguais que se estendem aos nossos dias.

Por essa razão, Marx será um incômodo muito grande aos idealismos educacionais, especialmente à ideologia de estado quanto a essa. Segundo ele, "desde que o trabalho começa a ser repartido, cada indivíduo tem uma esfera de atividade exclusiva que lhe é im- 
posta e da qual não pode sair" (Marx; Engels, 1975, p. 40). Logo, no contexto pós-Revolução Francesa, do qual a burguesia emerge como novo poder dominante, em oposição à nobreza do antigo regime, a educação se prestará à perpetuação dessa nova realidade, o que será novamente posto com a revolução proletária, quando o proletário, então, fará o mesmo uso da máquina educacional para criar e manter seu sistema de dominação. Assim, Marx (1975, p. 175) diz:

O trabalhador torna-se tanto mais pobre quanto mais riqueza produz, quanto mais a sua produção aumenta em poder e em extensão. $O$ trabalhador torna-se uma mercadoria tanto mais barata, quanto maior número de bens produz. Com a valorização do mundo das coisas aumenta em proporção direta a desvalorização do mundo dos homens. O trabalho não produz apenas mercadorias; produz-se também a si mesmo e ao trabalhador como uma mercadoria, e justamente na mesma proporção com que produz bens. Semelhante fato implica apenas que o objeto produzido pelo trabalho, $o$ seu produto, se lhe opõe como ser estranho, como um poder independente do produtor. O produto do trabalho é o trabalho que se fixou num objeto, que se transformou em coisa física, é a objetivação do trabalho. A realização do trabalho aparece na esfera da economia política como desrealização do trabalhador, a objetivação como perda e servidão ao objeto, a apropriação como alienação.

Logo, no século XXI, guardados os devidos contextos e proporções, há uma nítida comprovação da premissa usada por Marx quanto à valorização das coisas em detrimento das pessoas. Uma vez que o estado detém o monopólio da educação, essa se torna 
refém, subjugada, no vai e vem da maré ideológica, tornando-se a moeda de troca pelo poder econômico e político: as massas pedem mais educação; os que detêm poder econômico prometem atender esses anseios; o que é ofertado, caso clássico do Brasil, uma escola inepta sem a capacidade de produzir o esclarecimento, emancipação e autonomia humanas. Portanto, a escola atual está ideologicamente em harmonia com os que podem em sentido político e econômico ao passo que para os que dela dependem, especialmente em sentido social, haverá somente um jogo de manipulação e manobras.

\section{O DESENROLAR DA EDUCAÇÃO NO CONE SUL}

As Revoluções Atlânticas produziram uma nova ordem mundial e a necessidade de educação como direito de todos passou a fazer parte da preocupação dos legisladores. Para tanto, os países nos quais nos concentraremos, a saber, Argentina, Brasil, Chile e Uruguai, produziram leis complementares para efetivar o direito à educação. A Argentina produziu a lei 1.420 , de 8 de julho de 1884, dispondo sobre a educação nas escolas primárias argentinas; em 1905 a Lei Láinez a substituiu, fixando as diretrizes da educação naquele país. O Chile, em novembro de 1860, criou a Lei das Escolas Primárias, substituída pela lei 3.654, de 1920. O Uruguai, em decreto de 1848, regulou a instrução primária, atualizada pela Legislação Escolar de 1874. Todas essas nações, já no século XIX, mostravam preocupação com a regulamentação dos processos envolvidos no acesso e nos meios de prover a educação aos seus cidadãos.

O Brasil, infelizmente, não teve o mesmo esmero. Ainda que a Constituição outorgada em 1824 falasse sobre o direito à educação 
primária, a lei que trata do assunto não conseguiu abranger todos os aspectos relacionados à educação dos brasileiros. Alguns de seus artigos dizem:

Art. $1^{\circ}$ Em todas as cidades, vilas e lugares mais populosos, haverá as escolas de primeiras letras que forem necessárias.

Art. $6^{\circ}$ Os Professores ensinarão a ler, escrever as quatro operações de aritmética, prática de quebrados, decimais e proporções, as noções mais gerais de geometria prática, a gramática da língua nacional, e os princípios de moral cristã e da doutrina da religião católica e apostólica romana, proporcionando a compreensão dos meninos; preferindo para as leituras a Constituição do Império e a Historia do Brasil.

Art. $11^{\circ}$ Haverá escolas de meninas nas cidades e vilas mais populosas, em que os Presidentes em Conselho, julgarem necessário este estabelecimento.

Art. $15^{\circ}$ Estas escolas serão regidas pelos estatutos atuais no que se não opuserem á presente lei; os castigos serão os praticados pelo método de Lancaster (grifo nosso) (Brasil, Coleção de Leis do Império, 1827).

A lei imperial que dispunha sobre a criação das escolas de primeiras letras, embora buscasse garantir que os brasileiros tivessem acesso à educação elementar, não foi clara quanto às situações críticas como: os indígenas, que sempre foram instruídos pelos jesuítas até a expulsão desses por Pombal, em 1759, teriam acesso às escolas de primeiras letras? Os escravos teriam direito à educação? Os custos para educação existiam realmente. Como seria financiada? Por que a adoção do método Lancaster? Ensinar história do Brasil; qual história, se o Brasil como nação só se vê plenamente emancipado em 1840, com a ascensão de D. Pedro II ao trono? 
As respostas nós sabemos: os indígenas eram tidos como selvagens; logo, estavam excluídos da categoria de cidadãos. Os negros eram objetos, não tinham necessidade de educação. Quanto aos poucos que se qualificariam enfrentariam um problema muito sério: não havia pessoas qualificadas para ensinar, razão pela qual o Imperador adotou a pedagogia Lancaster. Esse método trabalhava da seguinte maneira: diante do problema da falta de professores, e da necessidade de ensinar para a massa, a solução veio com o elemento monitor. Estes eram alunos mais adiantados que recebiam, separadamente, orientações de um único professor e depois repassavam para os demais, os mais jovens, em números de dez, os decúrias. Neste processo, um único professor era capaz de lecionar, ao mesmo tempo, para um grupo imenso de alunos. Para que todo o processo funcionasse, $o$ procedimento de estímulo foi superior ao do castigo, instituindo uma nova forma de pensar a disciplina escolar (Araújo, 2010, p. 86-95).

De modo que podemos afirmar que a educação brasileira nasceu falida: sem recursos financeiros e humanos, o que dificultou a existência da escola pública para todos, prevista na Constituição. Em 1834, para acrescer dificuldades à educação, o governo da Regência providenciou uma Emenda Constitucional, chamada de Ato Adicional, que transferiu do governo imperial para as províncias a administração dos sistemas escolares e a implantação de escolas novas. Havia uma grande disparidade entre as províncias ricas como Rio de Janeiro, Minas Gerais, Pernambuco, Ceará e Bahia contra as que ainda não tinham recursos em abundância como São Paulo (nesse momento a província de São Paulo não era o gigante econômico de hoje), Grão-Pará, Goiás e Mato Grosso.

A consequência foi a estagnação e paralisação do sistema educacional para os pobres ao passo que os ricos continuavam a pagar por tutores qualificados, que os instruíam em seus lares e prepara- 
vam-nos para os estudos na Europa, em Coimbra ou nas instituições que existiam no Brasil, a Real Academia de Artilharia, Fortificação e Desenho, voltada ao ensino superior militar, a Faculdade Nacional de Medicina, em Salvador, as Faculdades de Direito de São Paulo e Pernambuco e a Faculdade Nacional de Direito do Rio de Janeiro, essas criadas no final do século XVIII e durante o século XIX. Além dessas poucas instituições públicas de ensino superior, que atendiam à ínfima pequena burguesia nacional, começaram a surgir as instituições privadas confessionais católicas e protestantes como os colégios batista, metodista e adventista e, em São Paulo, os presbiterianos com o Mackenzie College e a escola americana. Os pobres continuaram abandonados ao acaso.

A dinâmica colonial continuou inalterada: os que obtinham acesso aos organismos de educação pública eram pessoas da elite, filhos de fazendeiros, cafeicultores, donos de escravos etc. A população que realmente carecia de instrução pública de qualidade não tinha acesso à mesma, pela mesma razão que perdura até nossos dias: os mais pobres eram obrigados a trabalhar, especialmente os que residiam nas regiões rurais. Os que viviam nas áreas urbanas tinham que auxiliar na obtenção de alimentação para suas famílias. Quanto aos excluídos, especialmente os negros, assim permaneceram por muitos anos. Couty, numa viagem ao Brasil em 1881, chegou ao diagnóstico brasileiro: "O Brasil não tem povo", pois, "em nenhuma parte se acharão massas de eleitores sabendo pensar e votar, capazes de impor ao governo uma direção definida" (Couty, 1881, p. 87).

\section{O DESASTRE CHAMADO REPÚBLICA}

O final do século XIX foi uma desgraça para o Brasil: em 1888 o Império decreta a soltura dos escravos, os quais foram, a bem dizer, 
expulsos pelos seus antigos donos, lançados na miséria, sem possuir nenhum meio de sustentação ${ }^{2}$. Esse processo levou, no Rio de Janeiro e grandes cidades, ao surgimento das favelas, nos morros e arredores das cidades, onde estavam os escravos abandonados, alguns dos quais foram obrigados a se lançar na marginalidade com o intuito de obter o sustento. Caótico, o processo de abolição trouxe ao seio social milhões de pessoas que receberam repentinamente uma pretensa liberdade, mas que, em sua maioria absoluta, não sabiam ler, nem escrever. Tudo que sabiam era trabalhar, mas seus senhores se recusavam a tê-los como empregados, contratando antes os imigrantes europeus que começaram a desembarcar no Brasil na segunda metade do século XIX.

A República e sua constituição foi uma coisa asquerosa para a educação brasileira. Sendo a nova forma de governo fruto de um golpe de estado militar, sua preocupação foi maior em regular a educação das escolas militares do que legislar sobre a educação pública, que prosseguia sob os cuidados, agora dos estados federados e sua única preocupação, como lei máxima do país, foi se referir ao ensino nos estabelecimentos públicos como leigo (Constituição de 1891 , art. 72 , par. $6^{\circ}$ ). Numa emenda constitucional de 1926, o silêncio foi mantido e somente o mesmo comentário foi realizado. Em suma, o Brasil chegar a ser uma República não trouxe nenhum impacto positivo sobre a sua educação. Foram as manifestações e manobras da sociedade civil, especialmente dos educadores brasileiros que forjaram aos poucos a educação brasileira.

2 No texto da lei 3.353/1888, há somente uma frase relevante, dizendo que é declarada extinta a escravidão no Brasil. Porém, considerando que no Brasil vivemos quase quatro séculos desse mal, declarar a extinção importava não em findar um sistema econômico de produção, mas eliminar do cenário social todos os que eram esse sistema. Assim, intencionalmente ou não, em 1888 , foram extintos todos os que eram outrora escravos, negras e negros que vivem marginalizados até hoje, entregues à negligência e carência de políticas públicas de inclusão que possam corrigir as injustiças de séculos. Não é de se estranhar que essa parcela da população brasileira seja a principal vítima de violência, considerando que dos homicídios que ocorrem no Brasil, $77 \%$ são de pessoas negras, de acordo com o Anuário do Fórum de Segurança Pública. 


\section{A REGULAMENTAÇÃO DO SISTEMA EDUCACIONAL BRASILEIRO}

Os espaços educacionais do Brasil republicano eram os mesmos do período imperial, incluindo as Escolas Normais, públicas. A primeira e pioneira na América Latina foi a de Niterói, de 1830, e outras nove pelo território do império, porém, em províncias destacadamente mais ricas. Tais escolas providenciavam o curso de $1^{\circ}$ grau com habilitação para o magistério. Em 1890, já no período republicano, criou-se o Pedagogium, no então Distrito Federal, Rio de Janeiro. Destinado a funcionar como centro de pesquisas educacionais e museu pedagógico, foi um embrião dos cursos de Pedagogia no Brasil (Romanelli, 2013, p. 167, 168). O Pedagogium foi extinto em 1919, mas as escolas normais ou o curso normal, sofrendo alterações conforme o tempo, duraram até a promulgação da segunda LDB brasileira em 1996, que instituiu como requisito mínimo o ensino superior (licenciatura) para o exercício do magistério. A ação da República Velha quanto à educação foi muito tímida, quase nula.

Em 1924, educadores brasileiros começam a se mobilizar, inspirados pelo espírito renovador. Mesmo antes, havia ações isoladas que intentavam sensibilizar o poder público para a criação de políticas públicas para área da educação no Brasil. Naquele ano, fundouse a Associação Brasileira de Educação, um impulso ao clamor dos educadores por mudanças, inspirados no movimento escolarnovista que estava em seu auge mundo afora. A Escola Nova propunha o espaço escolar, não apenas como transmissão de conteúdo propedêutico, mas essa como mecanismo de interação entre educador, educando e a proposta de novos métodos educacionais, no qual o educando seria o protagonista do processo de aprendizagem. Agora 
a educação receberia a análise sob dois enfoques novos: o aspecto psicológico e o aspecto sociológico (Romanelli, 2013, p. 129-131).

Apenas com o golpe de estado de 1930 e ascensão de Getúlio Vargas ao poder, é que a educação receberá atenção do governo federal. Contudo, não pelos nobres motivos de atender às demandas educacionais brasileiras. $\mathrm{O}$ propósito imediato era atender às necessidades do país. A guerra de 1914-1918 e a quebra da bolsa de Nova York em 1929 geraram para o Brasil uma realidade nova no contexto mundial. A guerra levou as nações industrializadas a se fecharem para exportações e concentrarem suas indústrias na produção de material bélico. O Brasil que até então era importador de quase todos os seus produtos de uso diário, entra no processo de substituição das importações e começa a criar o embrião da indústria nacional. A crise do café, devido à quebra da bolsa de Nova York, levou o Brasil, essencialmente agrícola, a rever seu modelo de produção, iniciando seu processo tardio de industrialização pesada. Havia, contudo, um problema sério: não havia trabalhadores qualificados, faltava mão de obra para a nascente indústria brasileira. É por essa razão que o ilegítimo governo Vargas (1930-1932) passa a atentar para necessidade de se regular a educação.

A grande reformulação, na verdade, foi quanto ao ensino secundário. Apenas para nos situar, a estrutura de então era o curso primário de quatro anos, garantido pela Constituição desde 1824 e, à medida do possível, fornecido à população que dispusesse de recursos para tal, e o secundário, que abrangeria o que hoje conhecemos como Fundamental II e Médio. Francisco Campos organizou o ensino secundário, estabeleceu um currículo seriado, instituiu a frequência obrigatória, dividiu em dois ciclos, um fundamental e um complementar e a exigência de conclusão com aprovação nesse 
para ingresso ao superior. Também equiparou todos os estabelecimentos de ensino secundário ao padrão do Colégio Pedro II, no Rio de Janeiro e institui as inspeções federais, bem como normas para admissão de docentes, bem como criou a carreira do Inspetor Escolar (Romanelli, 2013, p. 136, 137).

Por esse motivo, em 1932, os 26 educadores pioneiros do Brasil lançaram o Manifesto dos Pioneiros da Educação Nova, em defesa, acima de tudo, da educação pública, gratuita, de qualidade e para todos os brasileiros e brasileiras. Seu manifesto, em parte dizia:

[...] Em nosso regime político, o Estado não poderá, decerto, impedir que, graças à organização de escolas privadas de tipos diferentes, as classes mais privilegiadas assegurem a seus filhos uma educação de classe determinada; mas está no dever indeclinável de não admitir, dentro do sistema escolar do Estado, quaisquer classes ou escolas, a que só tenha acesso uma minoria, por um privilégio exclusivamente econômico. [...] para ramificações posteriores em vista de destinos diversos, mas antes como a escola oficial, única, em que todas as crianças, de 7 a 15 anos, todas ao menos que, nessa idade, sejam confiadas pelos pais à escola pública, tenham uma educação comum, igual para todos [...] (Azevedo et al., 1932, p. 40, 44) (grifos nossos).

Não obstante o manifesto expusesse as chagas do sistema educacional que, incluindo a reforma de Campos, criara uma dualidade do ensino, sendo o primário profissionalizante para pobres e o ensino secundário e superior para ricos, ainda que suas observações fossem acertadas quanto à participação ativa do Estado em promover essa dualidade no sistema educacional, especialmente após a Reforma Campos, mesmo sendo a sua proposta de educação ampla 
e de qualidade para todos os cidadãos e cidadãs corretas, sua única conquista durou três anos. A elaboração da Constituição de 1934 tinha, no título V, capítulo II, "Da Educação e da Cultura", além de outros três artigos específicos (Constituição de 1946, art. $5^{\circ}$, inciso XIV, art. 121, alínea “j”, par. $4^{\circ}$ e Art. 138, alínea “b”), isso foi uma conquista do manifesto. Porém, em 1937, a conquista foi derrotada pelo Estado Novo e sua nova Constituição, de 1937.

Capanema promoveu a solução dos sonhos: fez do sistema educacional uma fábrica de mão de obra barata, composta pelos pobres, é claro, e manteve o ensino superior e de qualidade disponível à oligarquia, falida, mas ainda extremamente influente. A partir de 1942, começaram a ser promulgadas, por iniciativa de Capanema, as leis orgânicas do ensino, reformando vários ramos do ensino secundário. Em relação ao ensino técnico-profissional, foram instituídas a Lei Orgânica do Ensino Industrial, em 30 de janeiro de 1942, e a Lei Orgânica do Ensino Comercial, em 28 de dezembro de 1943.

Entretanto, como o governo não possuía a infraestrutura necessária à implantação em larga escala do ensino profissional, recorreu-se à criação de um sistema de ensino paralelo, em convênio com as indústrias, através de seu órgão máximo de representação, a Confederação Nacional da Indústria (CNI). Em 22 de janeiro de 1942, criou-se o então Serviço Nacional de Aprendizagem dos Industriários, rebatizado mais tarde como Serviço Nacional de Aprendizagem Industrial (Senai), organizado e dirigido pela CNI e mantido pela contribuição dos estabelecimentos industriais a ela filiados. Como escola-padrão do ensino industrial, foi inaugurada em maio de 1942 a Escola Técnica Nacional, no Rio de Janeiro, dirigida inicialmente por uma equipe de professores suíços. 
Em 9 de abril de 1942, foi promulgada a Lei Orgânica do Ensino Secundário, instituindo um primeiro ciclo de quatro anos de duração, denominado ginasial, e um segundo ciclo de três anos, que podia ser o curso clássico ou o científico. Assim, este último ciclo, que na Reforma Francisco Campos apresentava três opções, passou a ter apenas duas. Os novos currículos estabelecidos pela lei demonstravam, segundo Romanelli, uma "preocupação excessivamente enciclopédica e a predominância das matérias de cultura geral e humanística”. Por influência da Segunda Guerra Mundial, a lei instituiu a educação militar para os alunos do sexo masculino, com diretrizes pedagógicas fixadas pelo Ministério da Guerra. Reafirmou a educação religiosa facultativa, a educação moral e cívica como matéria obrigatória e a limitação às escolas mistas, recomendando que a educação secundária da mulher se fizesse em estabelecimento de frequência exclusivamente feminina (Romanelli, 2013, p. 157-163).

A Lei Orgânica do Ensino Secundário, também conhecida como Reforma Capanema, permaneceu em vigor até a aprovação da Lei de Diretrizes e Bases da Educação Nacional (LDB), em 1961. A lei 4.024/1961 foi, por incrível que pareça, a primeira lei específica de diretrizes para educação. Mas como o Brasil é escravizado às elites, de maneira inseparável e inexplicável, conseguiram incluir na LDB de 1961, uma aberração, incompreensível, algo que foge à compreensão quando se pensa num país carente de políticas públicas para educação pública:

Art. $1^{\circ} \mathrm{A}$ educação nacional, inspirada nos princípios de liberdade e nos ideais de solidariedade humana [...].

Art. $2^{\circ} \mathrm{A}$ educação é direito de todos e será dada no lar e na escola.

Parágrafo único: À família cabe escolher o gênero de edu- 
cação que deve dar a seus filhos.

Art. 95. A União dispensará a sua cooperação financeira ao ensino sob a forma de:

a) subvenção, de acordo com as leis especiais em vigor;

b) assistência técnica, mediante convênio visando ao aperfeiçoamento do magistério, à pesquisa pedagógica e à promoção de congressos e seminários;

c) financiamento a estabelecimentos mantidos pelos estados, municípios ou particulares, para a compra, construção ou reforma de prédios escolares e respectivas instalações e equipamentos de acordo com as leis especiais em vigor (grifos nossos).

Por bizarro que pareça, o Congresso Nacional, que deveria representar o povo, produziu a LDB das elites. Incluíram na lei que deveria democratizar a educação pública, gratuita e de qualidade, a obrigação do Estado de subvencionar estabelecimentos particulares de ensino. Ali, foi decretada a falência da escola pública e criada a dualidade da qualidade de ensino: o ensino privado, normalmente em institutos religiosos com séculos de tradição pedagógica, versus a sofrida escola pública. Se antes o problema de acesso à escola tinha o caráter excludente no sujeito de direito, $o$ estudante, agora o governo criou um critério excludente no objeto de direito, a escola: a privada, para os filhos das elites, custeada com verba pública, e a 'escola dos outros', pública, sem recursos suficientes para prover ensino de qualidade aos estudantes. Nesse ponto, chegamos ao que Darcy Ribeiro disse, em 1977: o que o país chamava de crise na educação, foi na verdade um projeto legalmente planejado, com o intuito de alienar a escola pública e seus discentes da participação na riqueza nacional. 


\section{CONSIDERAÇõES FINAIS}

Evidentemente que poderíamos discorrer muitas laudas acerca desse tema tão precioso. Porém, o que queríamos entender era por quê e quando iniciava o projeto de destruição da escola pública mencionado por Darcy Ribeiro. Em 1984, dando continuidade aos seus estudos, Ribeiro publicou o livro Nossa escola é uma calamidade, no qual ele menciona como a escola se tornou um mecanismo de exclusão social, marginalizando especialmente as minorias sociais, que são presentes em maior número na população e privilegiando uma ínfima quantidade de pessoas que detêm o poder econômico e político e do qual não abrem mão para compartilhar. Paulo Freire, um educador da época de 1961, em seu livro Pedagogia do Oprimido (1974), expôs a situação brasileira: "Estes, que oprimem, exploram e violentam, em razão do seu poder, não podem ter, neste poder, a força de libertação dos oprimidos e de si mesmos" (Freire, 2013, p. 41).

Em 1996, após um longo processo de negociação, o Brasil conseguiu uma LDB abrangente e revolucionária. Porém, fomos golpeados por problemas muito sérios, obras do acaso: o relator da lei, Darcy Ribeiro, a melhor pessoa para doutrinar a respeito, morreu dois meses depois. Uma alternativa para ajudar nos esclarecimentos sobre a LDB, Paulo Freire, morreu cerca de cinco meses após a promulgação. O resultado foi a perda da ligação entre os educadores da nova geração com a geração que viveu o contexto de 1961, mais, dos que conviveram com os educadores da Educação Nova, como Fernando de Azevedo e Anísio Teixeira. É muito estranho, mas a verdade é que, em termos de legislação, tínhamos em 1996 uma lei nova, arrojada e pessoas que não souberam operá-la. A prova disso foi o atraso em se implementar os muitos avanços previstos naquele diploma. 
Após a LDB de 1961, que condenou a escola pública à penumbra, chegou, como mencionamos, a ditadura civil-militar, que desmantelou completamente o sistema, especialmente após os criminosos acordos MEC-USAID. O resultado desse 'acordo' de submissão foi a extinção de disciplinas de desenvolvimento do raciocínio crítico como Filosofia, Educação Política, Latim e Sociologia e a exaltação da Educação Moral e Cívica, bem como uma distorção da OSPB (Organização Social e Política Brasileira), nos moldes do regime e para adestrar as pessoas para a submissão passiva à ditadura. Moreira Alves, sobre isso denunciou: "É evidente que os propósitos de independência do Brasil conflitam com os interesses diretos dos Estados Unidos. [...] A educação é um instrumento de independência [...]" (Alves, 1968, p. 23).

Assim sendo, o que vemos hoje na educação brasileira, apesar de termos universalizado o ensino fundamental, com taxa de matrícula em torno de $95 \%$, ainda enfrentamos o problema da educação infantil, que atende apenas $24,6 \%$ das crianças até 3 anos; cerca de $18 \%$ não acessam a educação infantil; no ensino fundamental, cerca de $15 \%$ são reprovados no terceiro e do quinto ao nono anos; enquanto as salas de ensino fundamental têm, em média, 20 estudantes, no ensino médio o número é de 32 , chegando a 50 , dependendo da localização da escola (MEC, Censo Escolar, 2015). Embora o Brasil em 2015 tenha sancionado a lei 13.005 sobre o Plano Nacional de Educação (PNE), como sempre com metas ambiciosas, não age em conformidade com suas metas.

O fato é que o Brasil tem uma habilidade retórica excepcional: produzimos uma série de leis, decretos e emendas constitucionais para resguardar a educação, mas não conseguimos livrá-la dos seus grandes inimigos: as pessoas que esperam manter a população em ignorância controlada: podem saber, mas não o necessário; pre- 
cisam aprender, mas somente o básico; devem ser inseridas, mas jamais incluídas. $O$ fato é que se não passarmos ao exercício, especialmente no direito, da dialética, sempre seremos o país que cria leis, promulga leis, mas não produz justiça ou benefícios às massas. Perpetuaremos a triste realidade brasileira quanto à lei: ela serve a poucos; normalmente, aos que podem pagar para acessar ao Judiciário por meio dos profissionais habilitados para tal. Enquanto isso, as multidões das periferias, dos interiores e pobres, especialmente negros, mulheres e indígenas dos rincões brasileiros, multidões minorizadas (não existem minorias, especialmente ao falarmos de negros e mulheres que são a maioria da população; porém, tendo seus direitos negados, essas populações são minorizadas, esquecidas, pela sociedade e pelo estado), continuarão aquém dos benefícios da educação.

Em 2015 o Fundeb (Fundo Nacional da Educação Básica) determinou gasto anual por estudante de R\$2.545,31 (Brasil, Diário Oficial, 6 nov. 2015, p. 11). Enquanto isso, o CAQi (Custo AlunoQualidade Inicial), mecanismo criado pela Campanha Nacional pelo Direito à Educação, que traduz em valores o quanto o Brasil precisa investir por aluno ao ano, em cada etapa e modalidade da educação básica pública, para garantir, ao menos, um padrão mínimo de qualidade do ensino recomendado, era de $\mathrm{R} \$ 5.499,02$ (Campanha Nacional Educação). Para agravar o quadro, no final de 2016 foi aprovada a PEC 55 que congelará gastos e, por tabela, investimentos do governo federal pelos próximos 20 anos, sem que se tenha feito qualquer ressalva quanto aos investimentos em educação.

Adicionalmente, por Medida Provisória (746), o governo federal, num paradoxo, altera a estrutura do Ensino Médio, cuja evasão chega a $17 \%$, intencionando torná-lo fragmentado e integral, ou 
seja, as duas principais razões da evasão, desinteresse acadêmico e necessidade de trabalho, agora se tornam institucionais. É, como disse Ribeiro, um projeto para manter pobres, negros e diversas minorias alienadas da escola. Não temos uma crise educacional, temos um projeto de educação que é desenhado para ampliar a exclusão social. Todos esses ajustes foram aprovados em meses pelo Congresso Nacional, reconhecido por sua morosidade. Exemplo disso é a criação do imposto sobre grandes fortunas, previsto na Constituição de 1988 (art. 153, inciso VII), mas que até hoje não foi votado.

A conclusão a que chegamos é que o problema da educação brasileira é antigo, vem dos tempos em que fomos invadidos pelos europeus (portugueses, holandeses, franceses, ingleses etc.) e segue o mesmo procedimento metódico desde a Colônia: a educação de qualidade é um direito assegurado aos que podem pagar por ela. Aos demais, iguais, porém diferentes, restam as migalhas de um sistema público em ruínas, destruído por um projeto pernicioso de governo que calculadamente transformou a escola pública num depósito de pessoas, sem funcionalidade social ou cidadã. A conta a pagar já está à disposição: a quarta maior população carcerária do planeta, com o custo por pessoa em detenção de aproximadamente R \$ 40.000,00/ano. Sem dúvidas, uma clara demonstração de quão caro está custando o projeto mencionado por Darcy Ribeiro. Estamos perdendo preciosos recursos humanos para o tráfico, para o crime e para alienação social, não porque essas pessoas assim desejaram, mas porque criamos o sistema ideal para que elas sejam ejetadas como meros objetos da sociedade em que vivemos.

Levar a educação brasileira de um exercício retórico, discursivo e, algumas vezes, sofístico, ao dialético materialista é um exercício de estado e de povo. A ideologia, cujo poder se mostra em grande proporção, não pelo povo ser, como desejam os que conduzem a 
nação, "faminto, xucro e feio" (Ribeiro, 2011, p. 56), mas pela devida manipulação que leva a população a acreditar que nela esteja o defeito é uma estratégia, assim como o desmonte da educação, especialmente após o regime de 1964, é clarificado pelas políticas adotadas pelos militares que serviam de sombra dos civis que realmente controlavam e governavam o país, cabendo aos militares o trabalho sujo (Silva, 2017, p. 57).

O regime de 1964, segundo o suposto acordo e discurso, renovaria a educação brasileira. Fez acordos para alinhar o Brasil à escola dos Estados Unidos, mas não o fez com o nível superior. Mas a razão era muito simples: a educação superior não era objeto da ideologia do regime, mas a educação básica sim. Era importante que as pessoas comuns aderissem àquele projeto funesto de terror $\mathrm{e}$ medo, o que conseguiram. Obtendo o apoio dos milhões que compunham as massas, tanto o regime de 1964 como os seus herdeiros possibilitaram manter o povo cativo às mazelas e canalhices da classe política brasileira, fato que vivemos até o momento. Os privilegiados pelo ensino superior, sendo uma minoria, seriam somente um eco sibilante, sem muita expressão.

Por esse motivo, mesmo tendo um povo tão bravio, feliz, criativo e corajoso, estamos sempre patinando num lamaçal, agora exposto como nunca antes. Obviamente que, ao invés de assumir sua culpa nesse imbróglio todo, nem as classes economicamente dominantes, nem as politicamente ativas são culpadas, mas somente o povo. É uma conta que sempre fica para as massas: suportar a malversação dos recursos públicos, feita sem qualquer receio pelos políticos brasileiros e ainda serem responsabilizados por esse problema. Afinal, já que são apenas 'minorias', que sejam culpados e responsabilizados pelos crimes sociais que se comentem no país por uma multidão de poucas pessoas. 


\section{REFERÊNCIAS}

ALVES, M. M. Beabá dos MEC-USAID. Rio de Janeiro: Edições Gernasa, 1968.

ARAÚJO, J. S. Esboço sobre o surgimento, as características e a implantação do método monitorial/mútuo no Brasil do século XIX.

Cadernos da Pedagogia. São Carlos: Ano 4, v. 4, n. 7, 2010, p. 86-95.

AZEVEDO, F. de. Manifesto dos Pioneiros da Educação Nova.

Disponível em: <http://www.dominiopublico.gov.br/download/texto/ me4707.pdf >. Acesso em: 6 jun. 2017.

BOURDIEU, P; CAMPAGNE, Patrick. Os excluídos do interior. In: BOURDIEU, Pierre. A miséria do mundo. Petrópolis: Vozes, 1993.

BRASIL. Carta Lei de 15 de outubro de 1827: Manda criar escolas de primeiras letras em todas as cidades, vilas e lugares mais populosos do Império. Disponível em: <http://www2.camara.leg.br/legin/fed/ lei_sn/1824-1899/lei-38398-15-outubro-1827-566692-publicacaooriginal90222-pl.html>. Acesso em: 6 jun. 2017.

BRASIL. Constituição da República dos Estados Unidos do Brasil de 24 fevereiro de 1891. Disponível em: <http://www2.camara.leg.br/legin/ fed/consti/1824-1899/constituicao-35081-24-fevereiro-1891-532699publicacaooriginal-15017-pl.html>. Acesso em: 6 jun. 2017.

BRASIL. Constituição da República dos Estados Unidos do Brasil de 16 de julho de 1934. Disponível em: <http://www.planalto.gov.br/ccivil_03/ Constituicao/Constituicao34.htm>. Acesso em: 6 jun. 2017.

BRASIL. Diário Oficial da União. n. 212, edição de 6 nov. 2015.

BRASIL. Lei 4.024 de 20 de dezembro de 1961: Fixa as Diretrizes e Bases da Educação Nacional. Disponível em: <http://www2.camara. leg.br/legin/fed/lei/1960-1969/lei-4024-20-dezembro-1961-353722publicacaooriginal-1-pl.html>. Acesso em: 6 jun. 2017.

CAMPANHA NACIONAL EDUCAÇÃO. Valores de referência para o CAQi para etapas e modalidades do Fundeb 2015. Disponível 
em: $<$ http://www.custoalunoqualidade.org.br/pdf/CAQi-CampanhaCNE-2015.pdf $>$. Acesso em: 10 jan. 2017.

COUTY, L. L'esclavage au Brésil. Paris: Librairie de Guillaumin, 1881, p. 87.

FREIRE, P. Pedagogia do oprimido. 54. ed. São Paulo: Paz e Terra, 2013.

MARX, K. Escritos de juventude: manuscritos de 1844. Lisboa: Edições 70, 1975.

MARX, K; ENGELS, F. A ideologia alemã. v. 1. Lisboa: Presença, 1975.

MINISTÉRIO DA EDUCAÇÃO. Censo escolar 2015: notas estatísticas. Disponível em: $<$ http://portal.mec.gov.br/index.php?option=com docman\&view $=$ download\&alias $=36521$-apresentacao-censo-escolardivulgacao-22032016-pdf\&Itemid=30192>. Acesso em: 6 jun. 2017.

MINISTÉRIO DA EDUCAÇÃO. Com o novo ensino médio, você tem mais liberdade para escolher o que estudar! Disponível em: $<$ https:// www.youtube.com/watch?v=kdERkLO3eTs $>$. Acesso em: 6 jun. 2017.

MINISTÉRIO DA EDUCAÇÃO. O novo ensino médio vai melhorar a educação dos jovens! Disponível em: <https://www.youtube.com/ watch?v=C-M_ewoa0iY\&t=2s $>$. Acesso em: 6 jun. 2017.

MINISTÉRIO DA EDUCAÇÃO. O novo ensino médio vai se mais estimulante e compatível com a sua realidade! Disponível em: $<$ https:// www.youtube.com/watch?v=Qp0_kuVNskk>. Acesso em: 6 jun. 2017.

RIBEIRO, D. Ensaios insólitos. Rio de Janeiro: Batel, 2011.

ROMANELLI, O. de O. História da educação no Brasil. 39. ed. Petrópolis: Vozes, 2013.

SILVA, M. J. Jamais esqueceremos: terrorismo de estado no Brasil. Rio de Janeiro: Lumen Juris, 2017.

UNESCO. Situación educativa de América Latina y el Caribe:

Hacia la educación de calidad para todos al 2015. Oficina Regional de Educación para América Latina y el Caribe. Santiago, Chile: Ediciones del Imbunche, 2013. 